\title{
Variation in hepatic regulation of metabolism during the dry period and in early lactation in dairy cows
}

\author{
H. A. van Dorland, ${ }^{\star}$ S. Richter, ${ }^{*}$ I. Morel,† M. G. Doherr, $\ddagger$ N. Castro, $\S$ and R. M. Bruckmaier*1 \\ *Veterinary Physiology, Vetsuisse Faculty, University of Bern, 3001 Bern, Switzerland \\ †Agroscope Liebefeld-Posieux (ALP), 1725 Posieux, Switzerland \\ †Exp. Clinical Research, DCR-VPH, Vetsuisse Faculty, University of Bern, 3001 Bern, Switzerland \\ §Department of Animal Science, Las Palmas de Gran Canaria University, Arucas 35413, Spain
}

\begin{abstract}
The purpose of this study was to investigate variations in hepatic regulation of metabolism during the dry period, after parturition, and in early lactation in dairy cows. For this evaluation, cows were divided into 2 groups based on the plasma concentration of $\beta$-hydroxybutyric acid (BHBA) in wk 4 postpartum (PP; group HB, BHBA >0.75 mmol/L; group LB, BHBA $<0.75 \mathrm{mmol} / \mathrm{L}$, respectively). Liver biopsies were obtained from 28 cows at drying off (mean $59 \pm 8$ $\mathrm{d}$ antepartum), on d 1, and in wk 4 and 14 PP. Blood samples were collected every 2 wk during this entire period. Liver samples were analyzed for mRNA abundance of genes related to carbohydrate metabolism (pyruvate carboxylase, PC; phosphoenolpyruvate carboxykinase, PEPCK; citrate synthase, CS), fatty acid biosynthesis (ATP citrate lyase, ACLY) and oxidation (acyl-CoA synthetase long-chain, ACSL; carnitine palmitoyltransferase 1A, CPT 1A; carnitine palmitoyltransferase 2, CPT 2; acyl-coenzyme A dehydrogenase very long chain, ACADVL), cholesterol biosynthesis (3-hydroxy3-methylglutaryl-coenzyme A synthase 1, HMGCS1), ketogenesis (3-hydroxy-3-methylglutaryl-coenzyme A synthase 2, HMGCS2), and of genes encoding the transcription factors peroxisome proliferator-activated receptor $\alpha(\operatorname{PPAR} \alpha)$, peroxisome proliferator-activated receptor $\gamma(\operatorname{PPAR} \gamma)$, and sterol regulatory element binding factor 1 (SREBF1). Blood plasma was assayed for concentrations of glucose, BHBA, nonesterified fatty acids, cholesterol, triglycerides, insulin, insulin-like growth factor-I, and thyroid hormones. In both groups, plasma parameters followed a pattern usually observed in dairy cows. However, changes were moderate and the energy balance in cows turned positive in wk $7 \mathrm{PP}$ for both groups. Additionally, the energy balance and milk yield were similar for both groups after parturition onwards. Significant group effects were found at drying
\end{abstract}

Received June 13, 2008.

Accepted November 4, 2008.

${ }^{1}$ Corresponding author: rupert.bruckmaier@physio.unibe.ch off, when plasma concentrations of triglycerides were higher in LB than in $\mathrm{HB}$, and in wk $4 \mathrm{PP}$, when plasma concentrations of glucose and IGF-I were lower in HB than in LB. Similarly, moderate changes in mRNA expression of hepatic genes between the different time points were observed, although HB cows showed more adaptive performance than LB cows based on changes in mRNA expression of PEPCKc, PEPCKm, CS, CPT $1 \mathrm{~A}, \mathrm{CPT} 2$, and PPAR $\alpha$. Part of the variation measured in this study was explained by parity. Significant Spearman rank correlation coefficients between the variables were not similar at each time point and were not similar between the groups at each time point, suggesting that metabolic regulation differs between cows. In conclusion, metabolic regulation in dairy cows is a dynamic system, and differs obviously between cows at different metabolic stages related to parturition.

Key words: liver, transition period, gene expression, cow

\section{INTRODUCTION}

The period of transition from late gestation to early lactation involves considerable metabolic adaptation in dairy cows. After parturition, the amount of energy and protein required for the maintenance of functions and milk production cannot be met, because feed intake is insufficient. This period is characterized by mobilization of body fat, protein, and mineral stores to satisfy the requirements for milk production and maintenance. Some cows are able to overcome this period of negative energy balance well, whereas others do not, and these latter cows may develop metabolic and related diseases such as ketosis, retained placenta, mastitis, displaced abomasum, laminitis, or reproduction problems (Goff and Horst, 1997). In the system of metabolic adaptation to lactation, the physiological transitions involved are reflected through changes of several parameters such as levels of glucose decrease, concentrations of BHBA and NEFA increase, concomitantly with related changes of endocrine systems. This complex system of adaptation occurs gradually and can differ considerably between cows (Jorritsma et al., 2003). 
The nutritional status of cows before calving may affect the dry matter intake after calving. Garnsworthy and Jones (1987) observed that leaner cows at parturition increased their dry matter intake in early lactation faster than heavy cows. Furthermore, there exists some variation in the mobilization of body fat among cows. In this respect, Hachenberg et al. (2007) proposed that the NEFA concentration during the first week postpartum (PP) is an indicator for adaptive performance. In our own previous study (Kessel et al., 2008) a wide variation in plasma concentration of plasma BHBA between dairy cows managed under similar conditions and fed during early lactation was observed. However, this variation between cows was not associated with individual differences in the energy balance, which was similar in all cows. The above mentioned studies indicate that there exists variation among cows in how they metabolically and physiologically adapt to lactation. The fact that some cows are able to deal with this metabolic challenge more successfully than others under similar management conditions implies that metabolic adaptation may have a genetic component (Wiener, 1983).

The liver plays a key role in the metabolic adaptation, through coordination and interconversion of nutrients to support pregnancy and lactation (Seifert and Englard, 1994; Reynolds et al., 2003). Genes that are important for hepatic adaptation are phosphoenolpyruvate carboxykinase (PEPCK) and pyruvate carboxylase (PC), which are described as rate-limiting enzymes for hepatic gluconeogenesis (Greenfield et al., 2000). Furthermore, the liver is challenged by plasma NEFA as a result of the mobilization of fat in early lactation to compensate the energy deficit. This is illustrated by Loor et al. (2005) who found mRNA expression of several hepatic genes of the lipid metabolism is changed during the transition period. Despite these findings, the mechanisms of hepatic regulation of metabolism in dairy cows are still not fully understood, including the differences in metabolic regulation between cows. The aim of the present study was to investigate the possible variation between cows for hepatic regulation of metabolism, and its relationship with blood metabolites and hormones. The hypothesis to be tested was that hepatic regulation of metabolism is different between cows and different between time points related to parturition.

\section{MATERIALS AND METHODS}

\section{Animals, Feeding, and Management}

The experimental procedures followed the Swiss Law on Animal Protection and were approved by the Committee of Animal Experiments of the Canton Fribourg,
Switzerland. The present study involved 28 multiparous dairy cows of parities 2 to 6 of the breed types Brown Swiss, Holstein, and Fleckvieh (Simmental $\times$ Red Holstein). Cows were held at the Swiss Federal Research Station Agroscope Liebefeld-Posieux (ALP), Posieux, Switzerland. The experimental cows had a mean BW of $681 \mathrm{~kg} \pm 63.5 \mathrm{~kg}$ (mean $\pm \mathrm{SD}$ ), and they had produced $26.1 \mathrm{~kg} \pm 5.0 \mathrm{~kg} / \mathrm{d}$ of milk in their previous lactation (based on a 305-d milk production). The animals in the present study were simultaneously used in a feeding experiment to assess the fatty acid composition in milk fat. The study started with drying off at $59 \pm 8$ $\mathrm{d}$ before the expected parturition and lasted until wk 14 PP. During the dry period, cows were fed similar diets composed of hay (DM basis, consisting of $59 \mathrm{~g}$ of $\mathrm{CP}$ per $\mathrm{kg}$ and $4.1 \mathrm{MJ}$ of $\mathrm{NE}_{\mathrm{L}} / \mathrm{kg}$ ) and concentrate. One group of cows received concentrate with animal fat, while the other group received sunflower seed as fat source in the concentrate (comparable chemical content on DM basis, consisting of $163 \mathrm{~g}$ of CP per $\mathrm{kg}, 239 \mathrm{~g}$ of crude fat (ether extract) per $\mathrm{kg}$, and $9.4 \mathrm{MJ}$ of $\mathrm{NE}_{\mathrm{L}} /$ $\mathrm{kg}$ ). Additionally, straw (DM basis, consisting of $23 \mathrm{~g}$ of $\mathrm{CP}$ per $\mathrm{kg}$ and $1.8 \mathrm{MJ}$ of $\mathrm{NE}_{\mathrm{L}} / \mathrm{kg}$ ) was always accessible. One week before parturition, cows were gradually adapted to the lactation diet, which was fed solely from parturition onwards. All cows received a common lactation diet, which was a mixture of grass silage (DM basis, consisting of $194 \mathrm{~g}$ of $\mathrm{CP}$ per $\mathrm{kg}$ and 6.6 MJ of $\mathrm{NE}_{\mathrm{L}} / \mathrm{kg}$ ), maize silage (DM basis, consisting of $76 \mathrm{~g}$ of $\mathrm{CP}$ per $\mathrm{kg}$ and $6.6 \mathrm{MJ}$ of $\mathrm{NE}_{\mathrm{L}} / \mathrm{kg}$ ), and potatoes (DM basis, consisting of $85 \mathrm{~g}$ of $\mathrm{CP}$ per $\mathrm{kg}$ and $7.7 \mathrm{MJ}$ of $\mathrm{NE}_{\mathrm{L}} / \mathrm{kg}$ ) in equal amounts. Additionally, minerals were fed, and an energy-rich concentrate (DM basis, consisting of $120 \mathrm{~g}$ of $\mathrm{CP}$ per $\mathrm{kg}$ and $8.0 \mathrm{MJ}$ of $\mathrm{NE}_{\mathrm{L}} /$ $\mathrm{kg}$ ), and a protein-rich concentrate (DM basis, consisting of $581 \mathrm{~g}$ of $\mathrm{CP}$ per $\mathrm{kg}$ and $8.1 \mathrm{MJ}$ of $\mathrm{NE}_{\mathrm{L}} / \mathrm{kg}$ ) were fed according to each cow's extra requirements for milk production. Hay (DM basis, consisting of $152 \mathrm{~g}$ of CP per $\mathrm{kg}$ and $6.2 \mathrm{MJ}$ of $\mathrm{NE}_{\mathrm{L}} / \mathrm{kg}$ ) and water were always accessible. During the entire study, cows were housed in a free-stall barn with permanent access to an enclosed yard outside. Cows were milked twice daily between 0445 and $0615 \mathrm{~h}$ and between 1600 and $1730 \mathrm{~h}$.

\section{BW, Milk Yield, and Energy Balance}

Cows were weighed individually at the beginning of the experiment, shortly after parturition, and in 4 and 14 wk PP. The energy balance was estimated for each cow, based on the recorded daily feed intake for each cow individually through electronic identification (responders) and controlled by feeding doors registering intake at each access through electronic feed balances (Insentec B.V., Marknesse, the Netherlands). 
Feed samples were collected regularly and pooled to form 3 to 4 samples per feed component, which were subsequently analyzed for chemical composition during routine analyses at the ALP Research station as described by Graf et al. (2005). Milk yield was recorded at each milking for each cow individually. Four times per week, milk samples were taken for the determination of the content of milk fat, protein, and lactose with a method used in routine milk control (CombiFoss 6000, Gerber Instruments AG, Effretikon, Switzerland) at the laboratory of the Holstein Association of Switzerland, Grangeneuve, Switzerland.

Energy balance was estimated as the difference between the energy intake [based on tabular values for $\mathrm{NE}_{\mathrm{L}}$ of feeds (ALP, 2007), and measured DMI per animal $]$ and the energy output $\left[\mathrm{NE}_{\mathrm{L}}\right.$ requirements for maintenance and milk production, determined from tabulated values and recommended equations according to ALP (2007)].

\section{Blood Collection and Analysis of Plasma Metabolites and Hormones}

Blood samples were taken from the jugular vein every 2 weeks between 0830 and $1000 \mathrm{~h}$ from drying off through 14 wk PP. Blood samples that were taken before parturition were allocated to 2-wk time-intervals represented by wk 2 (d 0-wk 2 antepartum; AP), wk 4 (wk 2-4 AP), wk 6 (wk 4-6 AP), wk 8 (wk 6-8 AP), and wk 10 AP (drying off, wk 8-10 AP), for convenience of analysis and representation of data. Blood samples that were planned in the weeks when a liver biopsy was also planned were taken on the same day, but before the liver biopsy. Blood samples were collected in evacuated tubes containing tri-potassium-EDTA and immediately put on ice. Plasma was obtained via centrifugation for $20 \mathrm{~min}$ at $1,500 \times \mathrm{g}$. Plasma for the determination of glucose, NEFA, BHBA, cholesterol, triglycerides, aspartate aminotransferase (ASAT), gamma glutamyltransferase (GGT), insulin, IGF-I, 3,5,3'-triiodothyronine $\left(\mathbf{T}_{\mathbf{3}}\right)$ and thyroxine $\left(\mathbf{T}_{\mathbf{4}}\right)$ was stored at $-20^{\circ} \mathrm{C}$ until analyzed.

Plasma concentrations of metabolites were measured enzymatically by using kits as described by Vicari et al. (2008). Concentrations of glucose, total cholesterol, and triglycerides and activities of ASAT and GGT were measured with kits from BioMérieux, Marcy l'Etoile, France (no. 61270, 61219, 61236, 63212, and 63712, respectively). Concentrations of NEFA were measured with kit no. 994-75409 from Wako Chemicals (Neuss, Germany), and BHBA with kit no. RB1007 from Randox Laboratories Ltd. (Ibach, Switzerland). Plasma insulin, IGF-I, $\mathrm{T}_{3}$, and $\mathrm{T}_{4}$ were measured by radioimmunoassay as described by Vicari et al. (2008).

\section{Liver Tissue Collection, RNA Extraction, and Quantitative Real-Time Reverse Transcription-PCR}

The liver of each cow was sampled at $10 \mathrm{wk}$ AP, d 1 PP, 4 wk PP, and in wk 14 PP by blind percutaneous needle biopsy (biopsy needle Tru Cut, Provet AG, Lyssach, Switzerland) under local anesthesia. Liver tissue (60-100 mg) was directly placed into an RNA stabilization reagent (RNAlater, Ambion, Applied Biosystems, Austin, TX) and stored at $-20^{\circ} \mathrm{C}$ until analyzed.

Total RNA was isolated from liver samples using peqGOLD TriFast (PEQLAB Biotechnologie GmbH, Erlangen, Germany) according to the manufacturer's instructions, and quantified by spectrophotometry with a BioPhotometer (Vaudaux-Eppendorf, Basel, Switzerland). For reverse transcription, $1 \mu \mathrm{g}$ of extracted total RNA was reverse transcribed with $200 \mathrm{U}$ of Moloney Murine Leukemia Virus Reverse Transcriptase RNAase H Minus, Point Mutant (Promega Corporation, Madison, WI) using $100 \mathrm{pmol}$ of random hexamer primers (Invitrogen, Leek, the Netherlands). The obtained cDNA was diluted to a final concentration of $25 \mathrm{ng} /$ $\mu \mathrm{L}$.

The enzymes selected and measured involved in lipid metabolism were ATP citrate lyase (ACLY), acyl-CoA synthetase long-chain (ACSL), carnitine palmitoyltransferase 1A (CPT 1A), carnitine palmitoyltransferase 2 (CPT 2), and acyl-coenzyme A dehydrogenase very long chain (ACADVL). The last 4 enzymes are involved in $\beta$-oxidation of fatty acids, whereas ACLY is involved in fatty acid and cholesterol biosynthesis. The measured enzymes, 3-hydroxy-3-methylglutaryl-coenzyme A synthase 1 and 2 (HMGCS 1 and $\mathbf{2}$, respectively) control reactions in the cholesterol biosynthesis and ketogenesis, respectively. Citrate synthase (CS), $\mathrm{PC}$, and cytosolic and mitochondrial phosphoenolpyruvate carboxykinase (PEPCKc and PEPCKm, respectively) were enzymes that were selected, because they are involved in carbohydrate metabolism. The measured peroxisome proliferator-activated receptor $\alpha$ (PPAR $\alpha)$, peroxisome proliferator-activated receptor $\gamma(\mathbf{P P A R} \gamma)$, and sterol regulatory element binding factor 1 (SREBF 1) are transcription factors predominantly involved in lipid metabolism. Intron-spanning primers were designed (see Table 1) to amplify cDNA from the above mentioned genes except for PEPCKm, PEPCKc, and PC, which were according to Hammon et al. (2003).

The PCR quantification was performed with the Rotor-Gene 6000 (Corbett Research, Sydney, Australia), using the software version 1.7.40. Fluorescence take off was calculated with the "second derivative maximum" program option. A master mix of the following reaction components was prepared: $1.8 \mu \mathrm{L}$ of water, $1.0 \mu \mathrm{L}$ of 
Table 1. Primer information, annealing temperature, and PCR product length

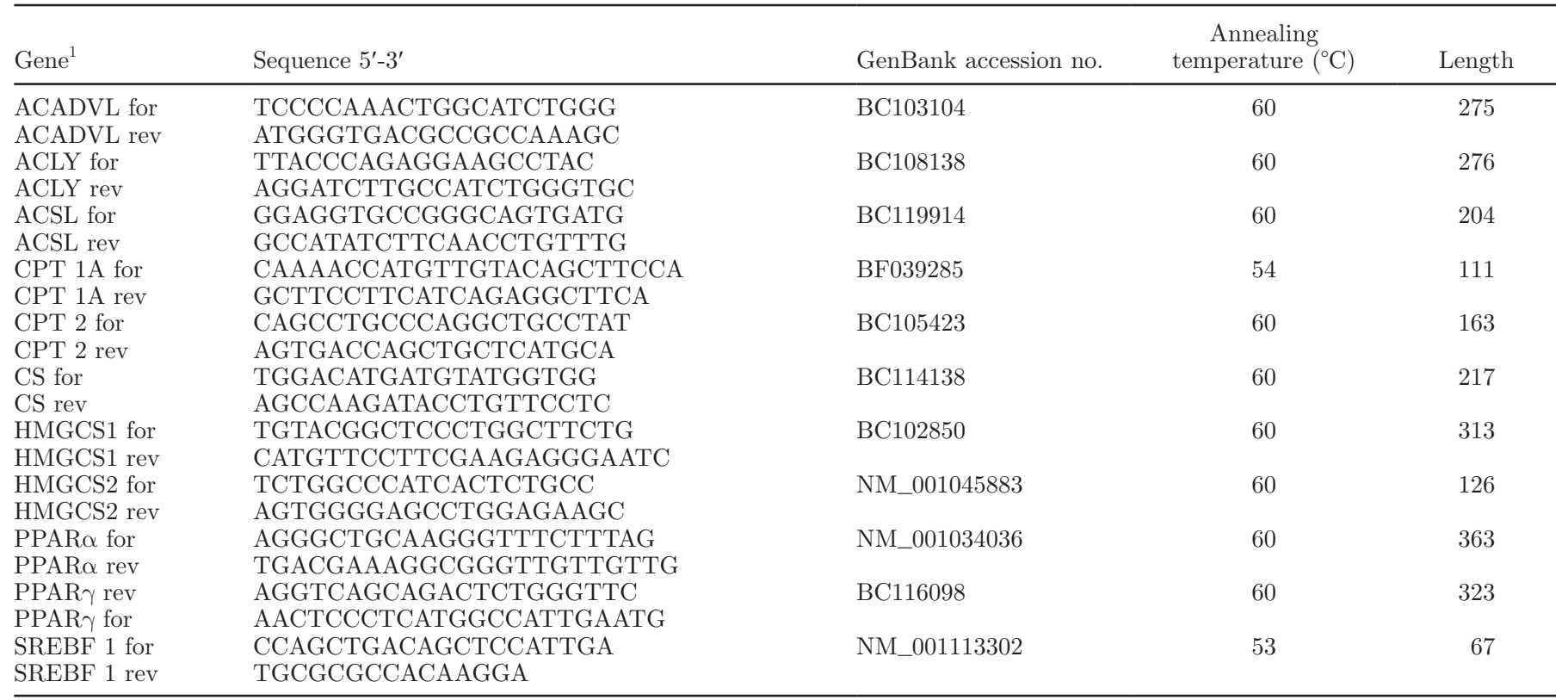

${ }^{1} \mathrm{ACADVL}=$ acyl-coenzyme A dehydrogenase very long chain; ACLY = ATP citrate lyase; ACSL = acyl-CoA synthetase long chain; CPT 1A $=$ carnitine palmitoyltransferase 1A; CPT $2=$ carnitine palmitoyltransferase $2 ; \mathrm{CS}=$ citrate synthase; HMGCS1 = 3-hydroxy-3-methylglutarylcoenzyme A synthase 1; HMGCS2 = 3-hydroxy-3-methylglutaryl-coenzyme A synthase 2; PPAR $\alpha=$ peroxisome proliferator activated receptor $\alpha ; \operatorname{PPAR} \gamma=$ peroxisome proliferator activated receptor $\gamma$; SREBF $1=$ sterol regulatory element binding factor 1.

forward primer $(5 \mathrm{pmol}), 1.0 \mu \mathrm{L}$ of reverse primer $(5$ pmol), $0.2 \mu \mathrm{L}$ of $50 \times$ SYBR Green $(20 \mathrm{pmol})$, and 5.0 $\mu \mathrm{L}$ of $2 \times$ SensiMix $(1 \mathrm{mM} \mathrm{MgCl} 2 ; 2 \times$ SensiMix NoRef DNA Kit). Nine microliters of master mix and $1 \mu \mathrm{L}$ of sample volume, containing $20 \mathrm{ng}$ of cDNA, were used. The following 3-step PCR program was used: denaturation for 10 min at $95^{\circ} \mathrm{C}, 40$ cycles of amplification (each consisting of $15 \mathrm{~s}$ at $95^{\circ} \mathrm{C}$, the primer-specific annealing temperature for $30 \mathrm{~s}$ (see Table 1), and extension at $72^{\circ} \mathrm{C}$ for $20 \mathrm{~s}$ and quantification of fluorescence), and finally a melting curve program $\left(60-95^{\circ} \mathrm{C}\right)$. The mRNA abundance was calculated relative to the expressions of the 2 reference genes, GAPDH and $\beta$-actin, which were observed to be stable across time points and between groups. The sequences of primers used for amplification of the 2 housekeeping genes were identical to Hammon et al. (2003).

\section{Statistical Analysis}

Statistical analysis of the data with the GLM procedure of SAS (2001), including concentrate type (animal fat or vegetable oil) as fixed effect, did not reveal a significant association of concentrate type for the tested variables measured in this study. Therefore, it was decided to disregard concentrate type as effect during further statistical analysis. Instead, to find differences between animals regarding their metabolism, cows were divided into 2 groups based on the plasma concentration of BHBA at wk $4 \mathrm{PP}$ (group $\mathrm{HB}(\mathrm{n}=$ 13), BHBA $>0.75 \mathrm{mmol} / \mathrm{L}$; group LB $(\mathrm{n}=15)$, BHBA $<0.75 \mathrm{mmol} / \mathrm{L}$, respectively]. Grouping was based on plasma concentrations of BHBA in wk $4 \mathrm{PP}$, because the occurrence of developing a ketosis in dairy cows is highest around that time (Holtenius and Holtenius, 1996). Therefore, increased concentrations of BHBA in early lactation during negative energy balance may be indicative for metabolic imbalance. However, the mean BHBA concentration measured in wk $4 \mathrm{PP}$ in this study $(0.83 \pm 0.07 \mathrm{mmol} / \mathrm{L}, \mathrm{n}=28)$ was relatively low compared with a BHBA concentration of $1.5 \mathrm{mmol} / \mathrm{L}$, which may represent a threshold value for subclinical ketosis (Busato et al., 2002). Moreover, the plasma BHBA concentration of $0.75 \mathrm{mmol} / \mathrm{L}$ in the present study represented the median concentration that split up the group of cows in 2 groups, which would benefit the statistical analysis. Subsequently, data were analyzed considering these 2 groups.

Data of plasma metabolites, enzymes and hormones, milk production, and energy balance were analyzed with a MIXED procedure of SAS, including week, group, parity $(2,3$, and $\geq 4)$, and the interaction week $\times$ group as fixed effects. Animal was used as repeated subject. Values in tables are presented as mean \pm SEM only for the 4 biopsy time points [wk 10 AP (drying off), within d 1 PP, wk 4 PP, and wk 14 PP]. Multiple 


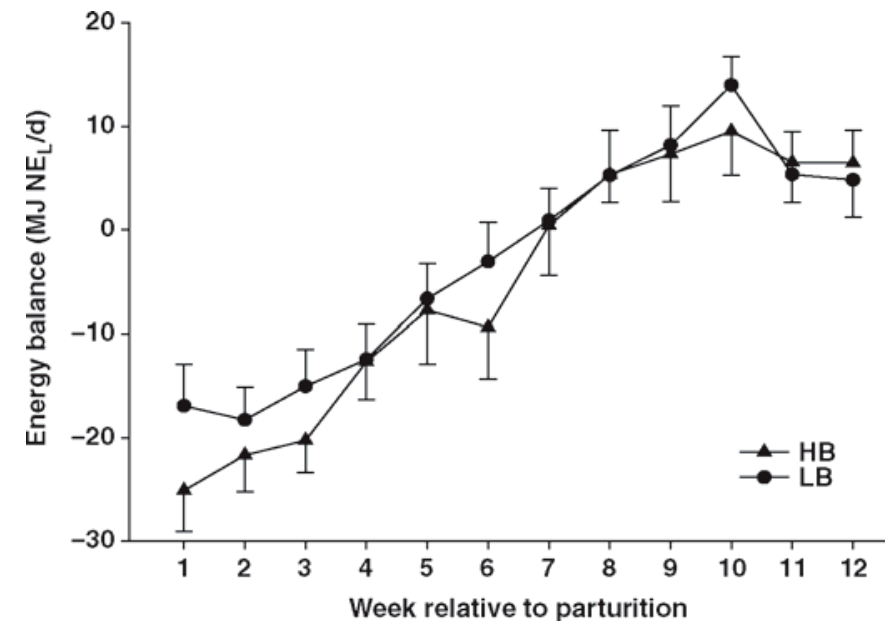

Figure 1. Average energy balance (mean \pm SEM; MJ $\mathrm{NE}_{\mathrm{L}} / \mathrm{d}$ ) of the cows from wk 1 until wk 12 postpartum.

comparisons between the means at each biopsy time point and comparisons between the 2 groups for each week during the entire experimental period were performed by the Bonferroni's t-test. Differences between means were considered significant if $P<0.05$.

Data of mRNA abundance $\left(\log _{2}\right)$ of hepatic genes were also analyzed with a MIXED procedure of SAS, but instead of including wk, biopsy time point was included in the same model as described above. Spearman rank correlation coefficients, adjusted for parity as a partial variable, were derived and plotted to identify possible (numerical) correlations between the intervalmeasured variables.

\section{RESULTS}

\section{BW Change, Milk Yield, and Energy Balance}

From wk 10 AP to parturition, cows in both groups had a similar loss of BW $(0.59 \pm 0.11 \mathrm{~kg} / \mathrm{d})$. Furthermore, each cow experienced a BW loss of $0.46 \pm 0.21$ $\mathrm{kg} / \mathrm{d}$ during the period from parturition to wk $4 \mathrm{PP}$, without any differences between the groups. From wk $4 \mathrm{PP}$ to wk $14 \mathrm{PP}$, no group differences were observed and cows gained $0.56 \pm 0.08 \mathrm{~kg} / \mathrm{d}$.

Milk production increased after parturition up to wk 6, and decreased thereafter up to wk 14 (not shown). Milk production was similar for LB $(26 \pm 1.7 \mathrm{~kg} / \mathrm{d})$ and for $\mathrm{HB}$ cows $(28 \pm 1.6 \mathrm{~kg} / \mathrm{d})$ in wk 2 PP. In wk 6 and $8 \mathrm{PP}$, milk production was significantly higher for cows in the LB group $(38 \pm 1.9$ and $37 \pm 2.0 \mathrm{~kg} / \mathrm{d}$, respectively) than for cows in the $\mathrm{HB}$ group $(36 \pm 2.4$ and $35 \pm 2.5 \mathrm{~kg} / \mathrm{d}$, respectively).

The calculated energy balance was negative up to wk $7 \mathrm{PP}$ and reached a peak in wk 10 PP. From wk 1 after parturition to wk $12 \mathrm{PP}$, the energy balance was similar in both groups (Figure 1).

\section{Plasma Metabolites, Hormones, and Enzymes}

Concentrations of BHBA remained relatively stable $\mathrm{AP}$ in both $\mathrm{LB}$ and $\mathrm{HB}$, and then slightly increased until 14 wk PP in group LB, but transiently increased in group $\mathrm{HB}$ to peak concentrations in wk 4 PP (Figure 2 ). The grouping based on plasma BHBA concentration in wk $4 \mathrm{PP}$ resulted in a significant difference between the groups $\mathrm{LB}$ and $\mathrm{HB}$ for concentrations of BHBA in wk 4 PP. Furthermore, cows of parity $\geq 4$ had, in general, higher BHBA concentrations than second-parity cows $(P<0.05)$. Additionally, a significant effect of parity $\times$ time was observed for BHBA concentrations. Mean concentration of NEFA was highest at 10 wk AP compared with the other biopsy time points PP in both groups and decreased thereafter until wk 4 (HB) and wk 2 (LB) AP (Figure 3). After parturition, NEFA concentration was highest in wk $2 \mathrm{PP}$ in both groups with a higher concentration in LB than in $\mathrm{HB}(P<0.05)$. Thereafter, NEFA concentration was decreased in both groups until wk 14 PP. A significant effect of parity was observed for NEFA concentrations, which showed cows of parity 2 and 3 to have generally lower NEFA concentrations than cows of parity $\geq 4$. No significant effect of group $\times$ time was observed. Concentrations of glucose remained relatively stable until parturition in both groups, transiently decreased in group HB until wk 2 PP, and then steadily increased up to wk 14 to levels measured before and until parturition. In wk $4 \mathrm{PP}$, glucose concentrations in HB group were significantly lower compared with the other biopsy time points, whereas concentrations PP did not significantly change in group LB (Figure 4). Glucose concentrations in wk 2 and wk $4 \mathrm{PP}$ were significantly lower in $\mathrm{HB}$ than in LB (Figure 4). Furthermore, no significant effects of parity and group $\times$ time interactions were observed. Cholesterol concentrations increased from wk 10 AP to wk 6 (LB) and wk 4 AP (HB) after which concentrations decreased in both groups until wk $2 \mathrm{PP}$ (not shown). After wk 2 PP, cholesterol concentrations in both groups increased up to wk $14 \mathrm{PP}$ in which highest concentrations were measured compared with the other biopsy time points $(P<0.05$; Table 2$)$. No group differences for concentrations of cholesterol were observed over time, but third-parity cows had in general significantly higher concentrations than cows of parity 2 and $\geq 4$. The triglyceride concentration in both groups decreased after parturition (d 1) and remained low in wk 4 and wk 14 PP. In HB cows, the triglyceride concentration was significantly lower than in LB cows in wk 6 and 8 AP (not shown). No significant effect 


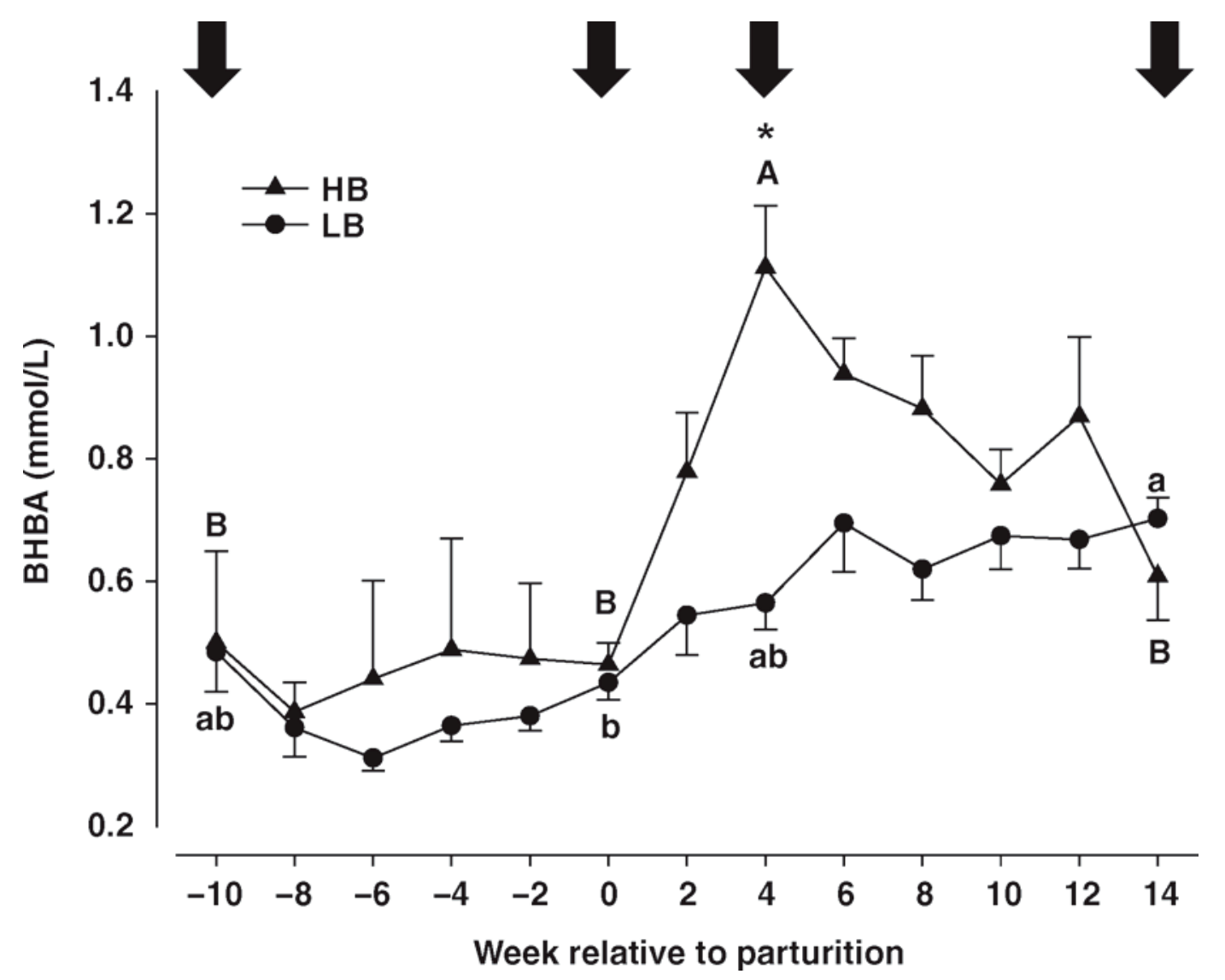

Figure 2. Patterns of plasma BHBA concentration (mean $\pm \mathrm{SEM} ; \mathrm{mmol} / \mathrm{L})$. Different capital letters $(\mathrm{A}, \mathrm{B})$ indicate differences $(P<0.05)$ at measured biopsy time points for cows with high BHBA concentrations ( $>0.75 \mathrm{mmol} / \mathrm{L}$ ) in wk $4 \mathrm{pp}$ (group HB). Means with different small letters $(\mathrm{a}, \mathrm{b})$ indicate differences $(P<0.05)$ at measured biopsy time points for cows with low BHBA concentrations $(<0.75$ mmol/L) in wk 4 pp (group LB). An asterisk $(*)$ indicates a significant difference $(P<0.05)$ between group HB and group LB at a given time point.

of parity on triglyceride concentrations was observed. The plasma activities of GGT, but not of ASAT, were affected by time, but differences of GGT activities were not localized on the 4 biopsy time points, and there were no group differences. However, cows of parity $\geq 4$, followed by second-parity cows had generally lower activities of GGT than cows of parity 3. In case of ASAT activities, in wk 6 and $4 \mathrm{AP}$ and in wk $14 \mathrm{PP}$, group $\mathrm{HB}$ had higher activities than group LB $(P<0.05)$, and cows of parity $\geq 4$ had generally lower activities than second and third-parity cows.

Concentrations of $T_{3}$ increased PP. In wk 14, the highest concentration of $\mathrm{T}_{3}$ was measured in both groups compared with the other biopsy time points $(P$ $<0.05$; Table 2). In wk 4 AP, group HB had lower $\mathrm{T}_{3}$ concentrations than group LB $(P<0.05$; not shown). Third-parity cows had highest $\mathrm{T}_{3}$ concentrations compared with second-parity cows and cows of parity $\geq 4$ $(P<0.05)$. Concentrations of $\mathrm{T}_{4}$ transiently decreased from wk 10 AP to d 1 PP $(P<0.05$; Table 2$)$. Significantly higher concentrations of $\mathrm{T}_{4}$ were measured in both groups in wk $14 \mathrm{PP}$ compared with d 1 after parturition $(P<0.05)$. No group differences and no significant effect of parity were observed for the concentration of $\mathrm{T}_{4}$ during the course of the study (Table 2). The $\mathrm{T}_{3} / \mathrm{T}_{4}$ ratio increased PP $(P<0.05)$. The $\mathrm{T}_{3} / \mathrm{T}_{4}$ ratio was lower in wk $10 \mathrm{AP}$ compared with the other biopsy time points $(P<0.05)$. In wk $4 \mathrm{AP}$, a higher ratio was measured in LB than in $\mathrm{HB}(P<0.05$; not shown). The $\mathrm{T}_{3} / \mathrm{T}_{4}$ ratio in third-parity cows, followed by cows of parity $\geq 4$, was significantly higher than in second-parity cows. Although concentrations of insulin were affected by time, differences in concentrations between weeks were not localized at the 4 biopsy time points, and did not differ between groups (Table 2). Additionally, no significant effect of parity on insulin concentrations was observed. The IGF-I concentration transiently decreased from wk $10 \mathrm{AP}$ to $\mathrm{d} 1 \mathrm{PP}$, and increased $\mathrm{PP}$ in both groups. In HB, highest concentrations were measured in wk $10 \mathrm{AP}$ and wk $14 \mathrm{PP}$ compared with the other biopsy time points $(P<0.05)$. In LB, the IGF-I concentration was significantly higher 


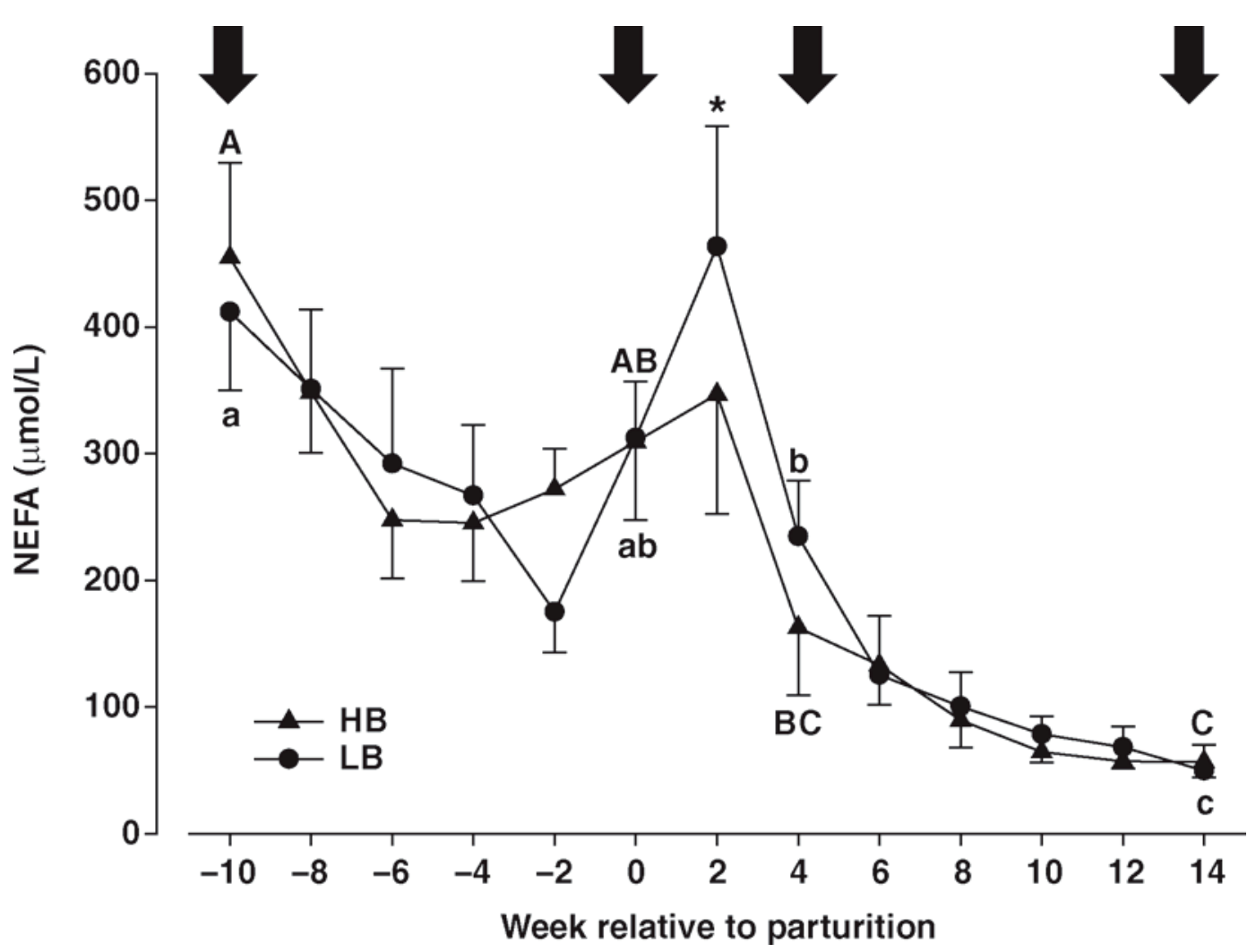

Figure 3. Patterns of plasma NEFA concentration (mean \pm SEM; $\mu$ mol $/ \mathrm{L})$. Different capital letters $(\mathrm{A}, \mathrm{B})$ indicate differences $(P<0.05)$ at measured biopsy time points for cows with high BHBA concentrations $(>0.75 \mathrm{mmol} / \mathrm{L}$ ) in wk 4 pp (group HB). Means with different small letters $(\mathrm{a}, \mathrm{b})$ indicate differences $(P<0.05)$ at measured biopsy time points for cows with low BHBA concentrations $(<0.75 \mathrm{mmol} / \mathrm{L})$ in wk 4 pp (group LB). An asterisk $(*)$ indicates a significant difference $(P<0.05)$ between group HB and group LB at a given time point.

in wk $10 \mathrm{AP}$, followed by the concentration in wk 14 $\mathrm{PP}$, compared with d $1 \mathrm{PP}$ and wk $4 \mathrm{PP}(P<0.05)$. A higher concentration of IGF-I for LB than for HB was measured throughout the study and was significant in wk 4 (Table 2), 6, 8, and $10 \mathrm{PP}(P<0.05$; not shown). Furthermore, second-parity cows, followed by thirdparity cows, had an overall significantly higher IGF-I concentration than cows of parity $\geq 4$.

\section{mRNA Abundance of Genes in the Liver Tissue}

The mRNA abundance of PC was similar over time and no significant time effect was measured in either group, and no group differences were measured for PC mRNA abundance over time (Table 3). The mRNA encoding for PEPCKm were affected by time and in group HB, but not in group LB, were higher on $\mathrm{d} 1$ $\mathrm{PP}$ than in wk $10 \mathrm{AP}(P<0.05)$, but there were no group differences. The mRNA encoding for PEPCKc showed a different pattern with less abundance on $\mathrm{d} 1$ $\mathrm{PP}$ and in wk $4 \mathrm{pp}$ than in wk $14 \mathrm{PP}(P<0.05)$, and more mRNA abundance $(P<0.05)$ in $\mathrm{HB}$ than LB cows in wk 10 AP (Table 3). Additionally, a significant effect of parity on mRNA abundance of PEPCKc was observed, with third-parity cows, followed by secondparity cows, having more mRNA abundance than cows of parity $\geq 4$ throughout the study. The mRNA encoding for CPT 1A and CPT 2 followed a similar pattern with the most mRNA abundance in wk $14 \mathrm{PP}$ and least abundance on d $1 \mathrm{PP}(P<0.05$; Table 3$)$ in group HB, but not in group LB. Furthermore, no group differences were observed for mRNA abundance of CPT $1 \mathrm{~A}$ and CPT 2 over time. In case of CPT 2, cows of parity $\geq 4$ had generally less mRNA abundance than secondand third-parity cows $(P<0.05)$. No significant effect of parity was observed for mRNA encoding for CPT $1 \mathrm{~A}$. Regarding the other genes related to $\beta$-oxidation, ACSL and ACADVL, no time or group effects were measured (Table 3). For both ACSL and ACADVL, mRNA abundance was generally lower for cows with parity $\geq 4$ than for second and third-parity cows $(P$ $<0.05)$. More mRNA abundance of CS was measured antepartum compared with postpartum $(P<0.05)$ in group $\mathrm{HB}$, but not in group LB, without significant dif- 


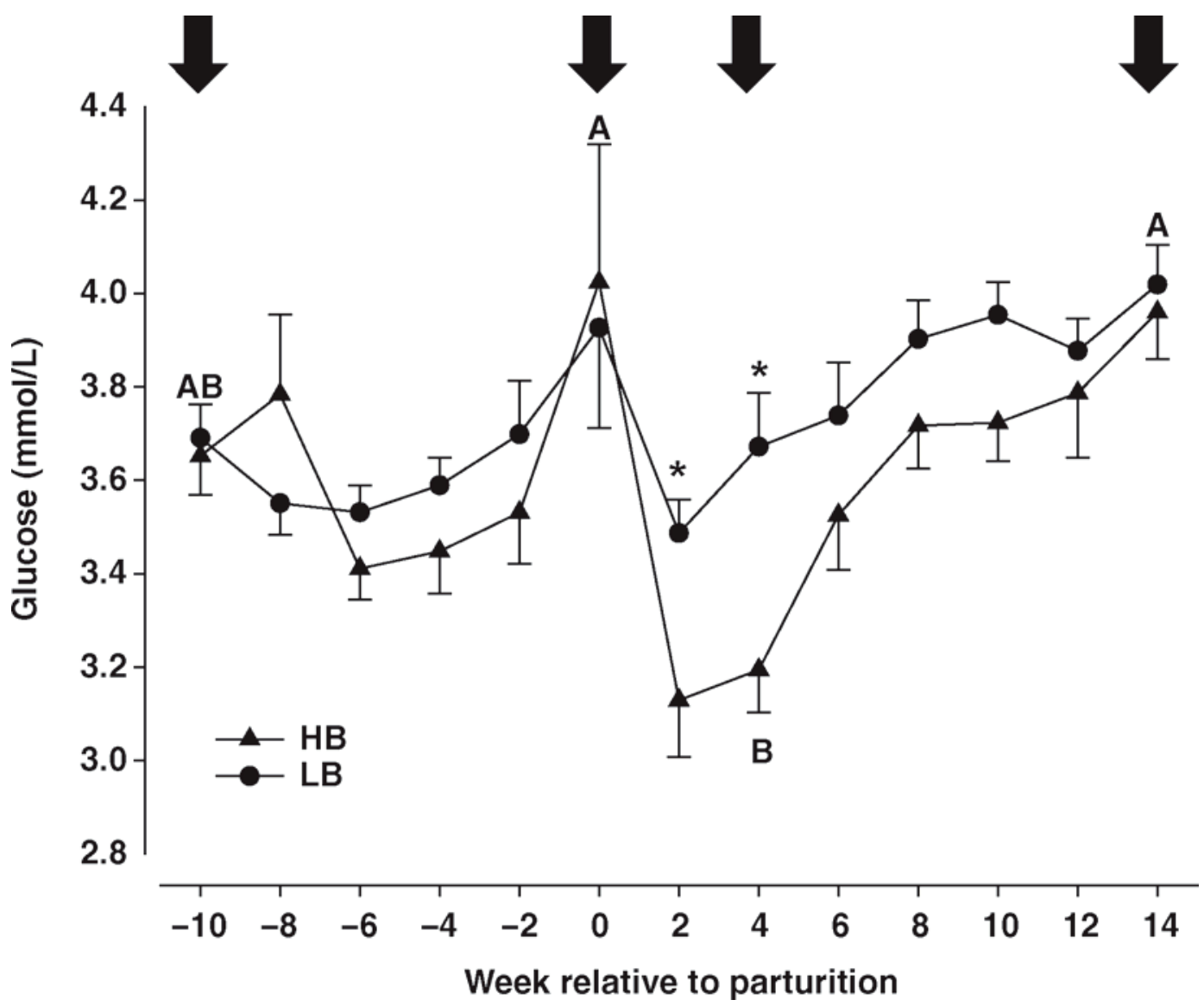

Figure 4. Patterns of plasma glucose concentration (mean \pm SEM; mmol/L). Different capital letters $(\mathrm{A}, \mathrm{B})$ indicate differences $(P<0.05)$ at measured biopsy time points for cows with high BHBA concentrations $(>0.75 \mathrm{mmol} / \mathrm{L}$ ) in wk 4 pp (group HB). Means with different small letters $(\mathrm{a}, \mathrm{b})$ indicate differences $(P<0.05)$ at measured biopsy time points for cows with low BHBA concentrations $(<0.75$ mmol/L) in wk 4 pp (group LB). An asterisk $(*)$ indicates a significant difference $(P<0.05)$ between group HB and group LB at a given time point.

ferences between groups over time (Table 3), but cows of parity $\geq 4$ had, in general, significantly higher mRNA encoding for CS than second and third-parity cows.

The HMGCS1 mRNA abundance increased PP and was highest in wk $4 \mathrm{PP}$ in group LB and in wk $14 \mathrm{pp}$ in group HB $(P<0.05$; Table 3$)$, with no significant group differences across time. Furthermore, mRNA encoding for HMGCS1 were generally lower for cows with parity $\geq 4$ than for second and third-parity cows $(P$ $<0.05)$. For ACLY and HMGCS2, changes of mRNA abundance were not significant over time and no group effects were measured (Table 3). Additionally, mRNA abundance of ACLY was generally less for cows with parity $\geq 4$ than for second and third-parity cows $(P<$ $0.05)$, and no significant effect of parity was observed for mRNA encoding for HMGCS2.

With regard to the selected transcription factors, only the mRNA encoding for PPAR $\alpha$ changed during the course of the study, being higher in wk $14 \mathrm{PP}$, followed by mRNA abundance at wk $10 \mathrm{AP}$, compared with d 1 and wk 4 PP $(P<0.05$; Table 4$)$. For PPAR $\alpha$, PPAR $\gamma$, and SREBF1, no group differences in abundance of mRNA were measured at the different biopsy time points during the study (Table 4). For PPAR $\alpha$ and PPAR $\gamma$ mRNA, but not for SREBF1 mRNA, a significant effect of parity was observed. In case of PPAR $\alpha$, mRNA abundance was generally less for cows with parity $\geq 4$ than for second- and third-parity cows. In case of PPAR $\gamma, \mathrm{mRNA}$ abundance of second-parity cows, followed by third-parity cows, was generally more than of cows of parity $\geq 4$.

\section{Correlations Between mRNA Abundance of Hepatic Genes and Plasma Metabolites, and Hormones}

Significant correlations $(P<0.05)$ between mRNA abundance of hepatic genes and blood plasma parameters at different biopsy time points around parturition for LB and HB are shown in Figures 5 and 6, respectively. In both groups, correlations (solid lines for positive, 
Table 2. Mean \pm SEM of plasma metabolites and hormones before and after parturition of dairy cows

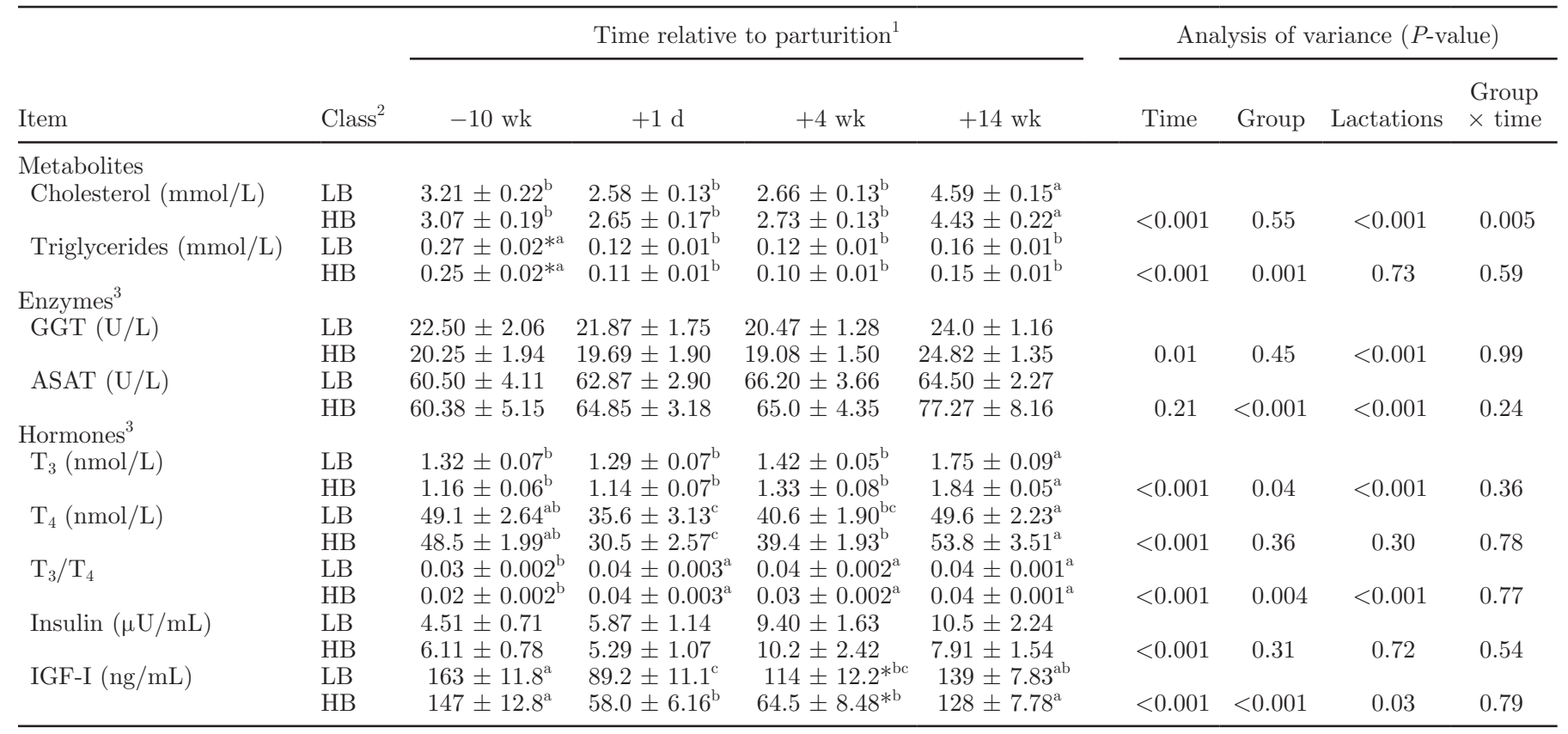

${ }^{\mathrm{a}-\mathrm{c}}$ Means within a row with different superscripts differ $(P<0.05)$. Means with $*$ indicate a difference between the 2 groups $(P<0.05)$.

${ }^{1}$ Significant differences in plasma concentrations between weeks were tested, but only results are presented in table for wk 10 antepartum, $1 \mathrm{~d}$, wk 4 and 14 postpartum.

${ }^{2}$ Grouped according to low (LB; $\left.<0.75 \mathrm{mmol} / \mathrm{L}\right)$ and high $(\mathrm{HB} ;>0.75 \mathrm{mmol} / \mathrm{L})$ plasma concentrations of BHBA in wk 4 after parturition.

${ }^{3} \mathrm{ASAT}=$ aspartate aminotransferase; GGT $=$ gamma glutamyltransferase; $\mathrm{T}_{3}=$ triiodothyronine; $\mathrm{T}_{4}=$ thyroxine

and dashed lines for negative correlations) among the measured parameters were not constant throughout the different biopsy time points, and correlations at each time point were not similar for both groups. The correlations shown had an $\mathrm{R}$-value of $>0.50$. In HB cows, $39 \%$ of the correlations had an $\mathrm{R}$-value ranging from 0.50 to 0.70 , followed by $48 \%$ of the correlations ranging from 0.70 to 0.90 , and $13 \%$ of the correlations with a R-value of $>0.90$. In LB cows, $63 \%$ of the correlations had an r-value ranging from 0.50 to 0.70 , followed by $35 \%$ of the correlations ranging from 0.70 to 0.90 , and $2 \%$ of the correlations with an R-value of $>0.90$.

For HB (Figure 5), least significant correlations were found in wk $10 \mathrm{AP}$ and wk $14 \mathrm{PP}$ (40 and 37 significant correlations (lines), respectively). On d $1 \mathrm{PP}$ and in wk $4 \mathrm{PP}$, a total of 73 and 71 significant correlations were observed in HB cows. For LB (Figure 6), fewer significant correlations were found on d 1 after parturition with 36 significant correlations, and in wk $14 \mathrm{PP}$ with 26 significant correlations. In wk $10 \mathrm{AP}$ and in wk $4 \mathrm{PP}$, a total of 48 and 61 significant correlations were observed in LB cows.

A total of 6 negative correlations (dashed lines) were observed between glucose and mRNA abundance of hepatic genes in wk $10 \mathrm{AP}$ for HB, but not for LB. After parturition, these correlations no longer existed.
Noticeable for the HB cows were the numerous positive correlations (solid lines) between the transcription factors and genes of the fatty acid oxidation and gluconeogenesis (except for PEPCKm) within $1 \mathrm{~d}$ PP and wk 4 PP. In case of LB, only PPAR $\alpha$ correlated with genes of the fatty acid oxidation on $\mathrm{d} 1 \mathrm{PP}$ and in wk $4 \mathrm{PP}$.

In wk $4 \mathrm{PP}$ for $\mathrm{HB}$, the $\mathrm{T}_{3}$ and especially $\mathrm{T}_{4}$ correlated with the mRNA abundance of several hepatic genes (4 and 7 significant correlations, respectively). This was not observed for LB, where instead many significant correlations between mRNA abundance of hepatic genes and the plasma parameters, IGF-I, glucose, insulin, and triglycerides were observed. In addition, most correlations between ACLY and other parameters were observed on $\mathrm{d} 1 \mathrm{PP}$ and in wk $4 \mathrm{PP}$ for $\mathrm{HB}$, and in wk $10 \mathrm{AP}$ and wk $4 \mathrm{PP}$ for LB. Finally, noticeable for $\mathrm{HB}$ cows in wk $4 \mathrm{PP}$ were 8 negative correlations observed between CS and other hepatic genes, whereas in wk $14 \mathrm{PP}$ correlations between CS and other hepatic genes were positive.

\section{DISCUSSION}

\section{Metabolic Status of Cows}

The high concentrations of NEFA in wk $10 \mathrm{AP}$ in both groups were also observed by Odensten et al. 
Table 3. Mean \pm SEM of mRNA abundance $\left(\log _{2}\right)$ of hepatic genes before and after parturition in dairy cows ${ }^{1}$

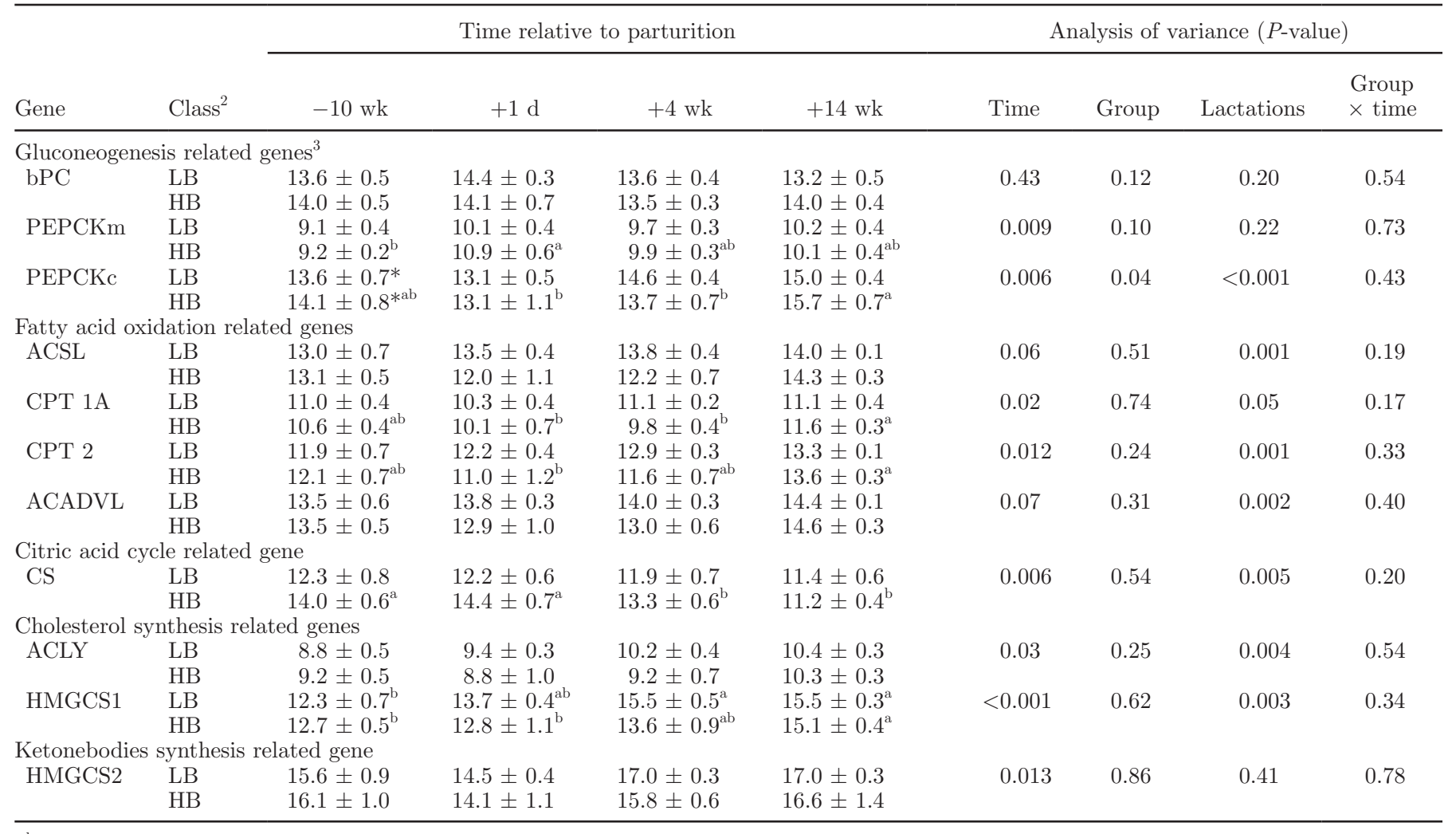

${ }^{\mathrm{a}, \mathrm{b}}$ Means within a row with different superscripts differ $(P<0.05)$. Means with * indicate a difference between the 2 groups $(P<0.05)$.

${ }^{1}$ mRNA abundance was calculated relative to the expressions of the two reference genes, GAPDH and $\beta$-actin.

${ }^{2}$ Grouped according to low (LB; $\left.<0.75 \mathrm{mmol} / \mathrm{L}\right)$ and high $(\mathrm{HB} ;>0.75 \mathrm{mmol} / \mathrm{L})$ plasma concentrations of BHBA in wk 4 after parturition.

${ }^{3} \mathrm{ACLY}=\mathrm{ATP}$ citrate lyase; ACADVL = acyl-coenzyme A dehydrogenase very long chain; ACSL = acyl-CoA synthetase long-chain; CPT $1 \mathrm{~A}$ $=$ carnitine palmitoyltransferase 1A; CPT $2=$ carnitine palmitoyltransferase 2 ; CS = citrate synthase; HMGCS1 = 3-hydroxy-3-methylglutarylcoenzyme A synthase 1; HMGCS2 = 3-hydroxy-3-methylglutaryl-coenzyme A synthase 2; PC $=$ pyruvate carboxylase; PEPCKc $=$ cytosolic phosphoenolpyruvate carboxykinase; PEPCKm = mitochondrial phosphoenolpyruvate carboxykinase.

(2007), and are possibly a consequence of a reduction of available nutrients at the start of the dry period, and the metabolic stress involved in adaptation to the new metabolic situation. The lack of a NEFA peak concentration shortly after parturition in this study was comparable with other studies (Blum et al., 1983) and suggests that cows in both groups did not experience enhanced lipolysis of adipose tissue at the onset of lactation and that the parturition stress was not marked. However, plasma NEFA concentrations increased during the first few weeks after parturition, followed by increasing concentrations of BHBA as has been observed previously (Busato et al., 2002; Hachenberg et al., 2007). In wk 4 PP, BHBA concentrations were higher in HB than in LB cows, although higher concentrations of NEFA were measured in wk $2 \mathrm{PP}$ for LB cows compared with HB cows. Busato et al. (2002) observed a NEFA peak concentration one week before the BHBA peak concentration in dairy cows. A rise of plasma BHBA concentrations due to enhanced ketogenesis may take some time after enhanced lipolysis, mirrored by elevated plasma NEFA levels. An explanation for our observation may be insufficiently frequent blood sampling.

The higher plasma BHBA concentration, as an indication of enhanced ketogenesis, in HB cows than in LB cows in wk $4 \mathrm{PP}$ coincided with a lower concentration of glucose in wk $4 \mathrm{PP}$ for $\mathrm{HB}$ cows than LB cows, which may suggest that HB cows suffered from a larger energy deficit than LB cows during the first weeks of lactation. However, this difference did not coincide with differences between the groups for the calculated energy balance and the daily weight loss during early lactation. Increased concentrations of plasma BHBA appear to be more sensitive and also more dynamic to indicate an energy deficit than calculations of energy balance, because increased plasma BHBA concentrations in HB cows may also be in part due to enhanced production 
Table 4. Mean \pm SEM of mRNA abundance $\left(\log _{2}\right)$ of nuclear receptors in the liver before and after parturition in dairy cows ${ }^{1}$

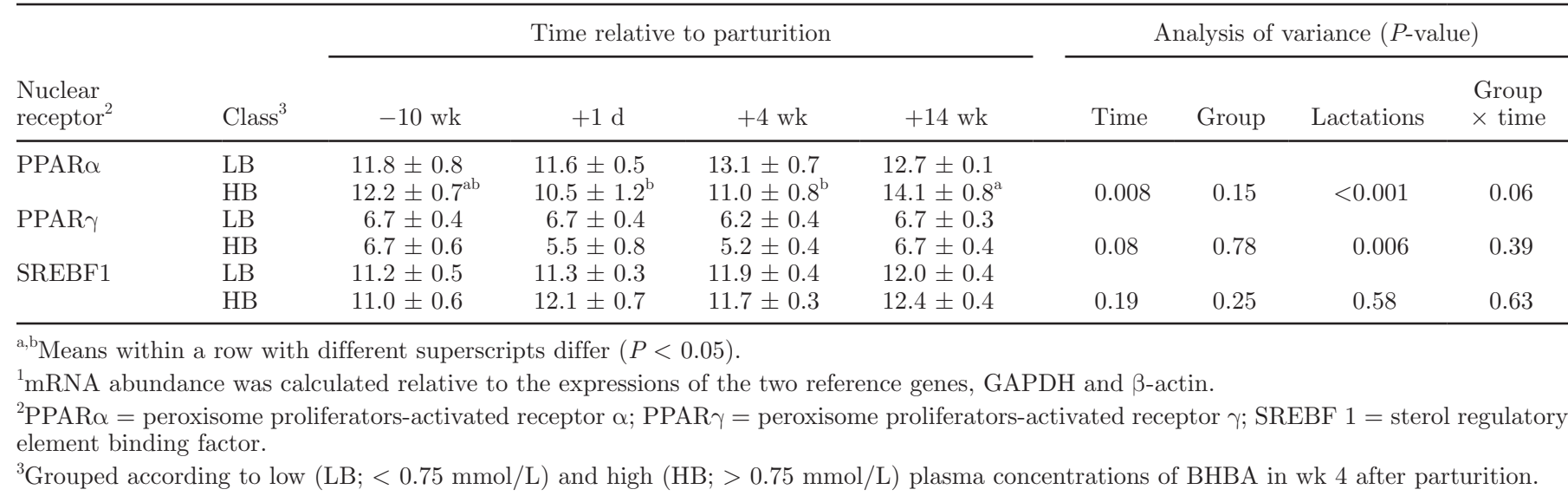

in the rumen wall and relatively independent from the energy balance. However, all cows received the same diet PP.

In both groups, the energy balance increased in parallel with glucose concentrations. That the energy balance had already become positive in wk $7 \mathrm{PP}$ indicates that cows were able to adapt quickly to lactation. The similar energy balance of cows in both groups was also reflected by the similar concentrations of insulin, $\mathrm{T}_{3}$, and $\mathrm{T}_{4}$, which are all indicators of energy status (Blum et al., 1983). In contrast, concentrations of IGFI differed between groups. Concentration of IGF-I is at its nadir during early lactation (Ronge et al., 1988), and is regulated by a large number of factors, including dietary protein and energy intake. On this basis, IGF-I concentrations may also represent an indicator of energy status as discussed in Hachenberg et al. (2007). However, a higher concentration of IGF-I in LB cows compared with HB cows was observed throughout the study, and could be explained by a genetically related difference between LB and HB cows for IGF-I concentration (Veerkamp et al., 2003).

The patterns of cholesterol and triglyceride concentrations in dairy cows were similar between LB and HB cows, and concentrations were in a range similar to observations in previous studies (Blum et al., 1983; Busato et al., 2002). Additionally, no group differences were observed for the parameters ASAT and GGT, which showed normal activity.

\section{Changes in mRNA Abundance of Hepatic Enzymes of the Gluconeogenesis}

In the present study, data on mRNA abundance of hepatic genes were used to describe metabolic function in addition to data on plasma concentrations of metabolites, hormones, and enzymes. Gene expression data provide only a snapshot of information regard- ing the quantity of a given transcript in a cell, but its assessment strengthens the functional parameters measured in this study.

The lack of significant changes in mRNA abundance of PC in both groups around parturition was surprising and may indicate that an increase of metabolism of gluconeogenic substrates after parturition did not occur, in contrast to findings from other studies (Greenfield et al., 2000; Murondoti et al., 2004). This may suggest that the energy demand at the onset of lactation was moderate in the cows of our study and cows were able to cover demands for gluconeogenesis. This may further be confirmed by the absence of marked increases in gene expression of PEPCKm and PEPCKc after parturition in LB cows. This was also observed by Greenfield et al. (2000) during the transition to lactation. However, they did observe an increased abundance of PEPCK mRNA following the transition period. The absence of these changes in the LB cows in our study suggest that hardly any endogenous protein was broken down to provide substrate for gluconeogenesis and the breakdown of triglycerides from adipose tissue and the provision of glycerol as a substrate for gluconeogenesis was only moderate following the transition period, as confirmed by the positive energy balance already at wk $7 \mathrm{PP}$.

The HB cows, however, showed higher mRNA expression of PEPCKm on d 1 after parturition than before parturition. In nonruminants, the expression of PEPCK mRNA is stimulated in the fasted state (Pilkis and Granner, 1992) and in cows, by the physiological state (Ballard et al., 1968). This may suggest that HB cows had reduced feed intake or experienced a shortage of energy shortly after calving due to the increased energy requirements for milk production and physiological recovery from pregnancy. The mRNA expression of PEPCKc in HB cows was lowest at d 1 after parturition compared with the other biopsy time points. This observation could imply an inhibition of mRNA expression 
of PEPCKc, possibly by insulin (Hanson and Reshef, 1997). However, because insulin concentrations on d 1 were similar in both $\mathrm{HB}$ and LB cows, other causes seem to be responsible for the effect.

\section{Changes in mRNA Abundance of Hepatic Enzymes of the $\beta$-Oxidation}

The ACSL regulates the first reaction in the fatty acid metabolism by catalyzing the activation of longchain fatty acids in the cytosol to acyl-CoA (Voet and
Voet, 2004). In the present study, the mRNA expression of ACSL in both groups did not increase one $\mathrm{d}$ after calving as observed by Loor et al. (2005). The lack of significant changes in mRNA expression of ACSL could suggest that the cows were in a metabolic state in which it is not necessary to cover energy requirements by enhanced oxidation of long-chain fatty acids (C12:0 to C18:0), mainly derived from the adipose tissue. This is also supported by the absence of significant changes in the mRNA expression of ACADVL in both groups, because ACADVL is one of the enzymes involved in
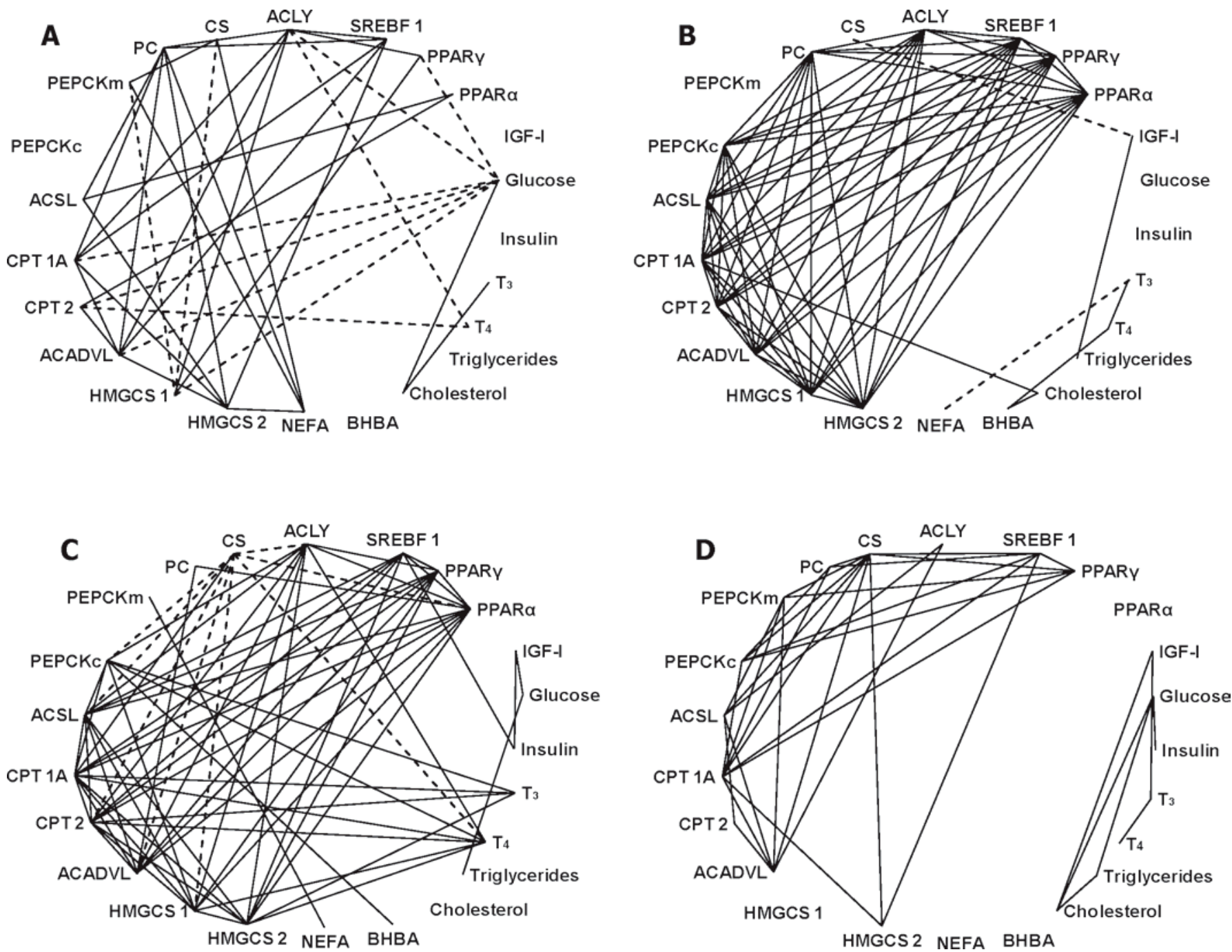

Figure 5. Correlations (Spearman rank correlation coefficients) among mRNA abundance of hepatic genes and concentrations of blood plasma in cows of the HB group (BHBA concentration $>0.75 \mathrm{mmol} / \mathrm{L}$ ) at $10 \mathrm{wk}$ antepartum (A), $1 \mathrm{~d}$ postpartum (B), 4 wk postpartum (C), and 14 wk postpartum (D). Only correlations are shown with $P<0.05$. Solid lines represent positive, and dashed lines represent negative correlations. ACADVL = acyl-coenzyme A dehydrogenase very long chain; ACLY = ATP citrate lyase; ACSL = acyl-CoA synthetase long-chain; CPT $1 \mathrm{~A}=$ carnitine palmitoyltransferase $1 \mathrm{~A}$; CPT $2=$ carnitine palmitoyltransferase 2; CS = citrate synthase; HMGCS1 = 3-hydroxy-3methylglutaryl-coenzyme A synthase 1; HMGCS2 = 3-hydroxy-3-methylglutaryl-coenzyme A synthase 2; PC = pyruvate carboxylase; PEPCKc $=$ cytosolic phosphoenolpyruvate carboxykinase PEPCKm = mitochondrial phosphoenolpyruvate carboxykinase; PPAR $\alpha=$ peroxisome proliferators-activated receptor $\alpha$; PPAR $\gamma=$ peroxisome proliferators-activated receptor $\gamma$; SREBF $1=$ sterol regulatory element binding factor 1 ; $\mathrm{T}_{3}=$ Triiodothyronine; $\mathrm{T}_{4}=$ Thyroxine . 
catalyzing the first step of the $\beta$-oxidation of long chain fatty acids.

The carnitine palmitoyltransferase system is necessary for the translocation of the fatty acyl-CoA into the mitochondria. Carnitine palmitoyltransferase 1A is believed to be a key regulatory step in long-chain fatty acids metabolism (McGarry and Brown, 1997). In the present study, the mRNA expression of CPT $1 \mathrm{~A}$ and CPT 2 did not increase after parturition in group LB and within the first 4 wk in group HB. Loor et al. (2005) observed increased mRNA expression of CPT 1A 1 d after parturition. Our contradictory findings may suggest that the influx of NEFA from the adipose tissue mobilization $1 \mathrm{~d}$ after parturition was not in a range that up-regulates the carnitine palmitoyltransferase system, likely be due to the absence of elevated NEFA concentration around calving. The highest mRNA expression of these 2 enzymes in wk 14 $\mathrm{PP}$ compared with the other biopsy time points in LB cows is difficult to explain, especially because NEFA
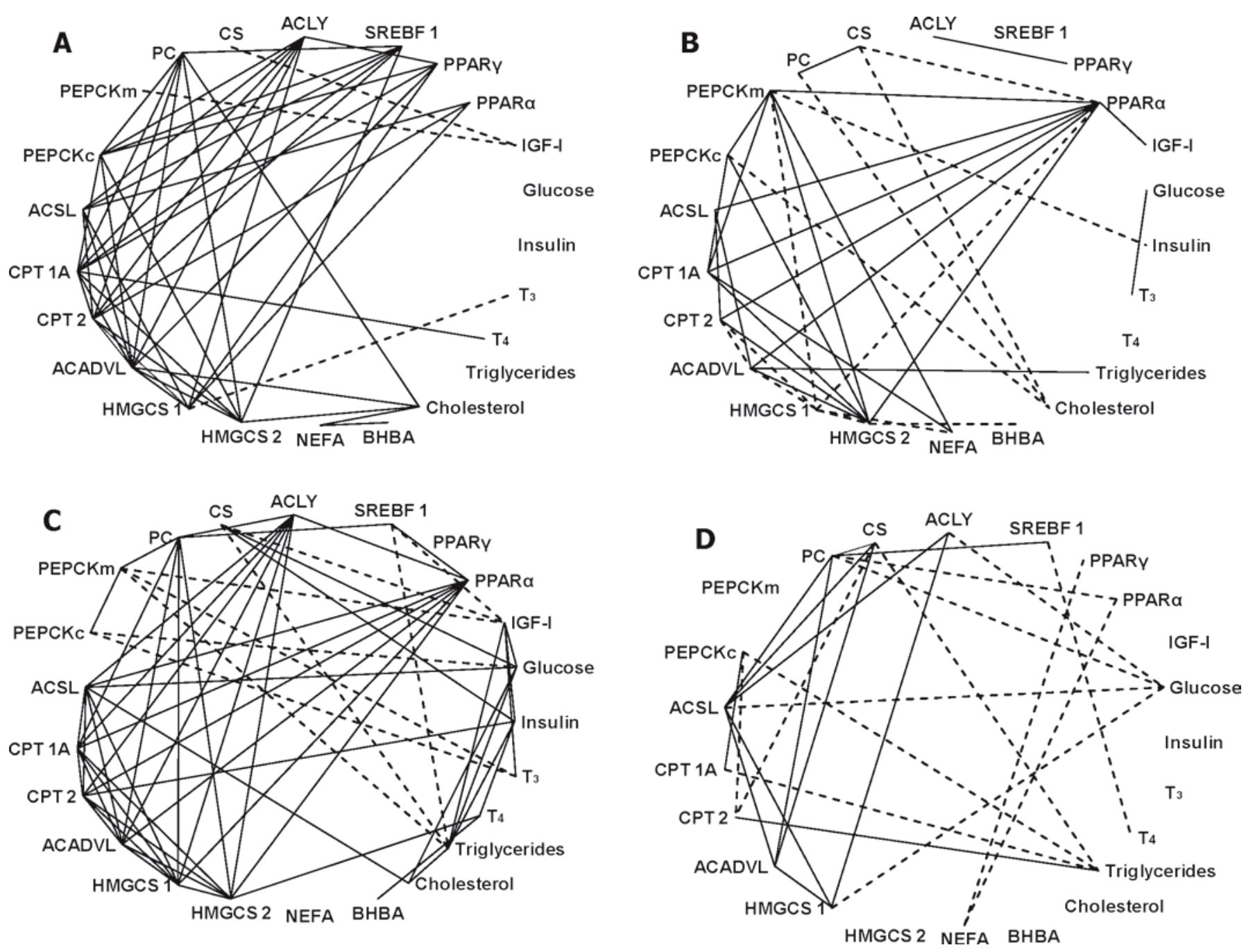

Figure 6. Correlations (Spearman rank correlation coefficients) among mRNA abundance of hepatic genes and concentrations of blood plasma in cows of the LB group (BHBA concentration $<0.75 \mathrm{mmol} / \mathrm{L}$ ) at 10 wk antepartum (A), $1 \mathrm{~d}$ postpartum (B), 4 wk postpartum (C), and 14 wk postpartum (D). Only correlations are shown with $P<0.05$. Solid lines represent positive, and dashed lines represent negative correlations. ACADVL = acyl-coenzyme A dehydrogenase very long chain; ACLY = ATP citrate lyase; ACSL = acyl-CoA synthetase long-chain; CPT $1 \mathrm{~A}=$ carnitine palmitoyltransferase 1A; CPT $2=$ carnitine palmitoyltransferase 2; CS = citrate synthase; HMGCS1 = 3-hydroxy-3methylglutaryl-coenzyme A synthase 1; HMGCS2 = 3-hydroxy-3-methylglutaryl-coenzyme A synthase 2; PC = pyruvate carboxylase; PEPCKc $=$ cytosolic phosphoenolpyruvate carboxykinase; PEPCKm = mitochondrial phosphoenolpyruvate carboxykinase; PPAR $\alpha=$ peroxisome proliferators-activated receptor $\alpha$; PPAR $\gamma=$ peroxisome proliferators-activated receptor $\gamma$; SREBF $1=$ sterol regulatory element binding factor 1 ; $\mathrm{T}_{3}=$ Triiodothyronine; $\mathrm{T}_{4}=$ Thyroxine. 
concentrations, which were observed to correlate positively with CPT 1A (Loor et al., 2005), were lowest in wk $14 \mathrm{PP}$ compared with the other time points.

\section{Changes in mRNA Abundance of Enzymes of Cholesterol Synthesis, Ketogenesis, Citric Acid Cycle, and Fatty Acid Synthesis}

Cholesterol synthesis and ketogenesis comprise an enzyme, HMGCS, which is common to both pathways. In the cytoplasm, HMGCS1 is involved in cholesterol biosynthesis, and in the mitochondria, HMGCS2 acts as a control enzyme in hepatic ketogenesis (Voet and Voet, 2004). The mRNA expression of HMGCS1 followed a pattern similar to the plasma cholesterol concentration in cows of both groups without any differences between the 2 groups. In this study, the proportional increase of the plasma concentration of insulin is known to increase cholesterol synthesis by increasing the activity of 3-hydroxy-3-methylglutaryl-coenzyme A reductase. This enzyme controls the reaction following the formation of 3-hydroxy-3-methylglutaryl-coenzyme A by HMGCS1 (Ness and Chambers, 2000). The mRNA abundance of HMGCS2 in the HB cows in wk 4 PP were surprisingly not higher than of LB cows, even though the BHBA concentration was significantly higher in wk $4 \mathrm{PP}$ in $\mathrm{HB}$ than in LB cows. Additionally in both groups, mRNA abundance was similar over time. In rats, Hegardt (1999) observed that HMGCS2 activity is increased by fasting. The absence of changes in gene expressions for HMGCS2 between groups and across the different time points in our study is unclear. A possible explanation could be that the synthesis of BHBA is regulated by posttranslational modification of the protein (Quant et al., 1990).

The CS catalyzes the condensation of acetyl-CoA and oxaloacetate to form citrate, which represents the first step in the citric acid cycle (Voet and Voet, 2004). The LB cows did not show any changes in mRNA abundance of the enzyme at the different time points, which may once more confirm that the metabolic load for the LB cows during the study was only moderate and an increase in the activity of the citric acid cycle in response to an increase in acetyl-CoA did not occur. The HB cows had increased mRNA abundance of CS in 10 wk $\mathrm{AP}$ and on $1 \mathrm{~d}$ after parturition, followed by a slightly lower mRNA abundance in 4 wk PP, and the lowest mRNA abundance in 14 wk PP. These results are supported by the observed negative energy balance that was apparent in $10 \mathrm{wk}$ AP (at least based on plasma NEFA concentrations), $1 \mathrm{~d}$ and 4 wk PP, which resulted in the mobilization of adipose tissue and enhanced supply of fatty acids for oxidation, thereby forming more acetyl-CoA.
The ACLY enzyme catalyzes a reaction that is similar to the reverse reaction catalyzed by the citrate synthase, and is mainly responsible for the supply of acetyl-CoA for synthetic pathways of fatty acids in nonruminants and preruminants (Drackley, 2000). In ruminants, the ACLY activity is low compared with nonruminants (Hanson and Ballard, 1967), because the major pathway for fatty acid synthesis is the formation of acetyl-CoA from acetate by cytosolic acetyl-CoA synthetase. This is mirrored by the lack of difference in mRNA expression of ACLY in cows between groups and over time in our study.

\section{Changes in mRNA Abundance of Hepatic Transcription Factors}

PPAR $\alpha$, is a ligand-activated transcription factor (also described as nuclear receptor), which is essential for the regulation of hepatic fatty acid metabolism. PPAR $\alpha$ mediates effects of NEFA on peroxisomal and mitochondrial fatty acid oxidation and up-regulates genes associated with ketogenesis (Mandard et al., 2004). However, in both LB and HB cows, the mRNA expression of PPAR $\alpha$, did not follow the expected pattern, corresponding to the measured NEFA concentration after parturition as observed in other studies (Janovick et al., 2004; Loor et al., 2005). Janovick et al. (2004) observed an increase in mRNA encoding for PPAR $\alpha$ in the liver of cows around parturition. Loor et al. (2005) observed a marked upregulation of PPAR $\alpha$ with increased serum NEFA. A possible explanation for our results could be the absence of peak concentration of NEFA around parturition and the moderate levels of plasma NEFA thereafter. On the other hand, the pattern of expression in $\mathrm{HB}$ cows was similar to the expression pattern of CPT $1 \mathrm{~A}$ and CPT 2, which may indicate a close association between PPAR $\alpha$ and the expression of these genes that are related to the fatty acid oxidation (Loor et al., 2005; see also next paragraph).

Peroxisome proliferator-activated receptor $\gamma$ (described as a transcription factor or nuclear receptor) is mainly expressed in adipose tissue (Rosen and Spiegelman, 2001) where it plays a central role in the control of adipocyte gene expression and differentiation. In the liver, the expression of this gene is low, but becomes elevated in fatty livers. Gavrilova et al. (2003) concluded from their study with mice that PPAR $\gamma$ in liver regulates triglyceride metabolism and contributes to fatty liver. The lack of significant changes in mRNA expression of PPAR $\gamma$ in cows of both groups may suggest that the cows did not develop a fatty liver. This was supported by low plasma activities of ASAT and 
GGT, indicating no measurable liver damage that could have occurred from a fat accumulation in the liver.

Sterol regulatory element binding factor 1 belongs to a family of transcription factors regulating the expression of enzymes involved in the cholesterol, fatty acid, triacylglycerol and phospholipid synthesis (Eberlé at al., 2004). Loor et al. (2005) observed a decrease in mRNA expression from $\mathrm{d}-30$ to $\mathrm{d}+1$ relative to parturition, followed by an increase until $\mathrm{d}+28$. We did not find changes in the mRNA expression of SREBF 1, even though the plasma concentration of cholesterol in our study changed over time.

\section{Hepatic Metabolic Regulation}

A main finding from the calculated correlations is that the correlations between gene expression of hepatic genes and blood plasma metabolites and hormones varied between late pregnancy and the different stages of lactation. This may be explained by the changes in the demand for nutrients and the extent of metabolic stress during the time from 10 wk AP until 14 wk PP, and the different physiological states during this period. Furthermore, at each time point, there were differences in the number of correlations and the type of correlations between the groups, which could suggest that metabolic regulation in cows of each group is different. In the HB cows, more correlations were observed at d 1 and in wk $4 \mathrm{PP}$ than in wk $10 \mathrm{AP}$ and wk $14 \mathrm{PP}$, which may indicate a higher metabolic activity in the liver on $\mathrm{d} 1$ and in wk 4 PP compared with the other time points. This may be explained by the typical mobilization of body fat, protein, and mineral stores to meet the requirements for milk production and maintenance during early lactation (Goff and Horst, 1997). In the LB cows, highest metabolic activity was observed in wk $4 \mathrm{PP}$, when the most significant correlations were counted. In contrast to the HB cows, the metabolic changes shortly after parturition affected the LB cows only moderately. This was also concluded from the results of the concentrations of metabolites and hormones for the LB cows.

Noticeable were the correlations between PPAR $\alpha$ and the genes of the fatty acid oxidation on $\mathrm{d} 1$ and in wk $4 \mathrm{PP}$ in both groups. This association was also observed by Loor et al. (2005), and confirms the suggestion that ACSL, CPT 1A, CPT 2, and ACADVL are target genes of this nuclear receptor, which is stimulated by reduced energy intake (Desvergne et al., 2006). In HB cows, but not in LB cows, we observed positive correlations between PPAR $\gamma$ and genes of the fatty acid oxidation (ACSL, CPT 1A, CPT 2, and ACADVL) on $\mathrm{d} 1$ and in wk $4 \mathrm{PP}$. These positive correlations indicate that increased fatty acid $\beta$-oxidation is followed by ketogenesis and fat accumulation in the liver. However, fat accumulation in the studied cows may have been minimal, because mRNA expression of PPAR $\gamma$ and ACLY were not increased after parturition compared with the other time points. Furthermore, as mentioned before, liver function was not impaired in cows of both groups, based on similar and normal activities of ALAT and ASAT.

The several negative correlations observed in wk 4 $\mathrm{PP}$, in HB cows, between citrate synthase and hepatic genes of the fatty acid oxidation may suggest an inhibition of this process. This inhibition may be explained by observations from Murondoti et al. (2004), who showed that in cows with triacylglyceride accumulation in the liver, fatty acid oxidation may be limited or depressed.

A further important finding was a positive correlation between plasma concentrations of $\mathrm{T}_{4}$ and mRNA expression of HMGCS2 in wk $4 \mathrm{PP}$ in $\mathrm{HB}$ and $\mathrm{LB}$ cows. This observation is supported by Heitzman et al. (1971). In their study, they observed that injection of $\mathrm{T}_{4}$ in early lactating cows increased the rate of ketogenesis. Additionally, in LB cows, a simultaneous significant correlation between plasma concentration of BHBA and gene expression of HMGCS2 was observed, which is a gene involved in ketogenesis. Noticeable too was that in HB cows, but not in LB cows, plasma concentrations of $\mathrm{T}_{4}$ also correlated significantly with mRNA abundance of HMGCS1, CPT 1A, CPT 2, PEPCKc, CS, and ACLY.

Furthermore, we did not find a significant correlation between the plasma concentration of NEFA and BHBA. Several studies found a positive correlation between plasma NEFA and BHBA (e.g., Hachenberg et al., 2007). The absence of this correlation in our study may be explained by a possible lag-time between the NEFA and BHBA peak concentrations, because NEFA provide the substrate for ketogenesis (Voet and Voet, 2004).

\section{Adaptive Performance and Effect of Parity on Metabolism}

Overall, the short-term and moderate energy demand of cows of both groups during early lactation was reflected by the few changes in relative mRNA expression of the hepatic genes measured at the different time points. Nevertheless, more significant differences between the different time points, regarding mRNA expression of hepatic genes, were observed for the HB cows compared with LB cows (see the paragraphs above), including the number of significant correlations at d 1 and wk $4 \mathrm{PP}$, which suggests that HB cows showed greater adaptive performance than LB cows. 
In the present study, parity had a significant effect on many of the measured parameters. Second-and third-parity cows in general showed a more favorable metabolic status than cows with parity of $\geq 4$, based on blood metabolites and hormone concentrations, which confirms observations of Lee and Kim (2006). In this respect, the less favorable metabolic status in cows of parity $\geq 4$ compared with second-and third-parity cows was supported by generally less mRNA abundance of the measured hepatic genes in our study.

\section{CONCLUSIONS}

The current study included novel aspects concerning metabolic regulation in dairy cows, because of its evaluation of variation between cows for metabolic regulation from the time of drying off to early lactation, and based on the grouping of cows having either high or low BHBA concentrations in wk $4 \mathrm{PP}$. The study showed that within a group of cows, similarly managed from wk 10 AP to wk $14 \mathrm{PP}$, variations between cows for metabolic regulation exist on the basis of the concentration of $\mathrm{BHBA}$ in wk $4 \mathrm{PP}$, and a considerable part of the variation resulted from this study is explained by parity. The observation that the pattern of correlations changed at the different time points shows, furthermore, that the regulation of hepatic metabolism is a dynamic system, and differs between cows at different metabolic stages related to parturition.

\section{ACKNOWLEDGMENTS}

We would like to thank Olga Wellnitz, Claudine Morel, Yolande Zbinden, Machabbat Saudenowa from the Veterinary Physiology group of the University of Bern, and Andreas Gutzwiller from the Agroscope LiebefeldPosieux for their technical support and assistance during sample collection and laboratory analyses. This study was supported by Swissgenetics (Zollikofen, Switzerland) and the Swiss Bundesamt für Landwirtschaft (BLW; Bern, Switzerland).

\section{REFERENCES}

ALP. 2007. Fütterungsempfehlungen und Nährwerttabellen für Wiederkäuer. Online edition. http://www.ALP.admin.ch/ dokumentation/00611/00631/index.html. Forschungsanstalt Agroscope Liebefeld-Posieux ALP, Posieux, Switzerland.

Ballard, F. J., R. W. Hanson, D. S. Kronfeld, and F. Raggi. 1968. Metabolic changes in liver associated with spontaneous ketosis and starvation in cows. J. Nutr. 95:160-173.

Blum, J. W., P. Kunz, H. Leuenberger, K. Gautschi, and M. Keller. 1983. Thyroid hormones, blood plasma metabolites and haematological parameters in relationship to milk yield in dairy cows. Anim. Prod. 36:93-101.

Busato, A., D. Faissler, U. Küpfer, and J. W. Blum. 2002. Body condition scores in dairy cows: Associations with metabolic and endocrine changes in healthy dairy cows. J. Vet. Med. A 49:455460.

Desvergne, B., L. Michalik, and W. Wahli. 2006. Transcriptional regulation of metabolism. Physiol. Rev. 86:465-514.

Drackley, J. K. 2000. Lipid metabolism. Pages 97-119 in Farm Animal Metabolism and Nutrition. J. P. F. D'Mello, ed. CAB International, Wallingford, UK.

Eberlé, D., B. Hegarty, P. Bossard, P. Ferré, and F. Foufelle. 2004. SREBF transcription factors: Masters regulators of lipid homeostasis. Biochimie 86:839-848.

Garnsworthy, P. C., and G. P. Jones. 1987. The influence of body condition at calving and dietary protein supply on voluntary food intake and performance in dairy cows. Anim. Prod. 44:347-353

Gavrilova, O., M. Haluzik, K. Matsusue, J. J. Cutson, L. Johnson, K. R. Dietz, C. J. Nicol, C. Vinson, F. J. Gonzalez, and M. L. Reitman. 2003. Liver peroxisome proliferator-activated receptor gamma contributes to hepatic steatosis, triglyceride clearance, and regulation of body fat mass. J. Biol. Chem. 278:34268-34276.

Goff, J. P., and R. L. Horst. 1997. Physiological changes at parturition and their relationship to metabolic disorders. J. Dairy Sci. 80:1260-1268.

Graf, C. M., M. Kreuzer, and F. Dohme. 2005. Effects of supplemental hay and corn silage versus full-time grazing on ruminal $\mathrm{pH}$ and chewing activity of dairy cows. J. Dairy Sci. 88:711-725.

Greenfield, R. B., M. J. Cecava, and S. S. Donkin. 2000. Changes in mRNA expression for gluconeogenic enzymes in liver of dairy cattle during the transition to lactation. J. Dairy Sci. 83:1228-1236.

Hachenberg, S., C. Weinkauf, S. Hiss, and H. Sauerwein. 2007. Evaluation of classification modes potentially suitable to identify metabolic stress in healthy dairy cows during the peripartal period. J. Anim. Sci. 85:1923-1932.

Hammon, H. M., S. N. Sauter, M. Reist, Y. Zbinden, C. Philipona, C. Morel, and J. W. Blum. 2003. Dexamethasone and colostrum feeding affect hepatic gluconeogenic enzymes differently in neonatal calves. J. Anim. Sci. 81:3095-3106.

Hanson, R. W., and F. J. Ballard. 1967. The relative significance of acetate and glucose as precursors for lipid synthesis in liver and adipose tissue from ruminants. Biochem. J. 105:529-536.

Hanson, R. W., and L. Reshef. 1997. Regulation of phosphoenolpyruvate carboxykinase (GTP) gene expression. Annu. Rev. Biochem. 66:581-611.

Hegardt, F. G. 1999. Mitochondrial 3-hydroxy-3-methylglutaryl-CoA synthase: A control enzyme in ketogenesis. Biochem. J. 338:569582 .

Heitzman, R. J., K. G. Hibbitt, and I. Mather. 1971. The effect of thyroxine on hepatic gluconeogenesis and ketogenesis in dairy cows. Eur. J. Biochem. 21:411-415.

Holtenius, P., and K. Holtenius. 1996. New aspects of ketone bodies in energy metabolism of dairy cows: A review. Zentralbl. Veterinarmed. A 43:579-587.

Janovick, N. A., J. J. Loor, H. M. Dann, H. A. Lewin, and J. K. Drackley. 2004. Characterization of changes in hepatic expression of inflammation-associated genes during the peripartum period in multiparous Holstein cows using quantitative real time-PCR (RTPCR). J. Dairy Sci. 87(Suppl. 1):460.

Jorritsma, R., T. Wensing, T. A. M. Kruip, P. L. A. M. Vos, and J. P. T. M. Noordhuizen. 2003. Metabolic changes in early lactation and impaired reproductive performance in dairy cows. Vet. Res. $34: 11-26$.

Kessel, S., M. Stroehl, H. H. D. Meyer, S. Hiss, H. Sauerwein, F. J. Schwarz, and R. M. Bruckmaier. 2008. Individual variability in physiological adaptation to metabolic stress during early lactation in dairy cows kept under equal conditions. J. Anim. Sci. 86:29032912.

Lee, J.-Y., and I.-H. Kim. 2006. Advancing parity is associated with high milk production at the cost of body condition and increased periparturient disorders in dairy herds. J. Vet. Sci. 7:161-166.

Loor, J. J., H. M. Dann, R. E. Everts, R. Oliveira, C. A. Green, N. A. Janovick Guretzky, S. L. Rodriguez-Zas, H. A. Lewin, and J. K. Drackley. 2005. Temporal gene expression profiling of liver from 
periparturient dairy cows reveals complex adaptive mechanisms in hepatic function. Physiol. Genomics 23:217-226.

Mandard, S., M. Müller, and S. Kersten. 2004. Peroxisome proliferatoractivator receptor $\alpha$ target genes. Cell. Mol. Life Sci. 61:393416.

McGarry, J. D., and N. F. Brown. 1997. The mitochondrial carnitine palmitoyltransferase system. From concept to molecular analysis. Eur. J. Biochem. 244:1-14.

Murondoti, A., R. Jorritsma, A. C. Beynen, T. Wensing, and M. J H. Geelen. 2004. Unrestricted feed intake during the dry period impairs the postpartum oxidation and synthesis of fatty acids in the liver of dairy cows. J. Dairy Sci. 87:672-679.

Ness, G. C., and C. M. Chambers. 2000. Feedback and hormonal regulation of hepatic 3-hydroxy-3-methylglutaryl coenzyme A reductase: The concept of cholesterol buffering capacity. Proc. Soc. Exp. Biol. Med. 224:8-19.

Odensten, M. O., B. Berglund, K. Persson Waller, and K. Holtenius 2007. Metabolism and udder health at dry-off in cows of different breeds and production levels. J. Dairy Sci. 90:1417-1428.

Pilkis, S. J., and D. K. Granner. 1992. Molecular physiology of the regulation of hepatic gluconeogenesis and glycolysis. Annu. Rev. Physiol. 54:885-909.

Quant, P. A., P. K. Tubbs, and M. D. Brand. 1990. Glucagon activates mitochondrial 3-hydroxy-3-methylglutaryl-CoA synthase in vivo by decreasing the extent of succinylation of the enzyme. Eur. J. Biochem. 187:169-174.

Reynolds, C. K., P. C. Aikman, B. Lupoli, D. J. Humphries, and D. E. Beever. 2003. Splanchnic metabolism of dairy cows during the transition from late gestation through early lactation. J. Dairy Sci. 86:1201-1217.

Ronge, H., J. W. Blum, C. Clément, F. Jans, H. Leuenberger, and H. Binder. 1988. Somatomedin C in dairy cows related to energy and protein supply and to milk production. Anim. Prod. 47:165183.

Rosen, E. D., and B. M. Spiegelman. 2001. PPAR $\gamma$ : A nuclear regulator of metabolism, differentiation, and cell growth. J. Biol. Chem. $276: 37731-37734$

SAS Institute. 2001. SAS/STAT User's Guide. Version 8.2. SAS Institute Inc. Cary, NC.

Seifert, S., and S. Englard. 1994. Energy metabolism. Pages 323-364 in The Liver, Biology and Pathobiology. 3rd ed. I. M. Aris, J. L. Boyer, N. Fausto, W. B. Jakoby, D. A. Schachter, and D. A. Shafritz, ed. Raven Press Ltd., New York, NY.

Veerkamp, R. F., B. Beerda, and T. van der Lende. 2003. Effects of genetic selection for milk yield on energy balance, levels of hormones, and metabolites in lactating cattle, and possible links to reduced fertility. Livest. Prod. Sci. 83:257-275.

Vicari, T. J. J. G. C. van den Borne, W. J. J. Gerrits, Y. Zbinden, and J. W. Blum. 2008. Postprandial blood hormone and metabolite concentrations influenced by feeding frequency and feeding level in veal calves. Domest. Anim. Endocrinol. 34:74-88.

Voet, D., and J. G. Voet. 2004. Fundamentals of Biochemistry. 3rd ed. John Wiley and Sons, New York, NY.

Wiener, G. 1983. Genetic aspects of "production disease" in ruminants. Pages 57-67 in V Int. Conf. Prod. Disease in Farm Animals, Uppsala, Sweden. 